\title{
Frequent fragility of randomized controlled trials for HCC treatment
}

\author{
Hao Zhang ${ }^{1}$, Jingtao $\mathrm{Li}^{2^{*}}$ and Wenting Zeng ${ }^{1^{*}}$ (D)
}

\begin{abstract}
Background: The fragility index (FI) of trial results can provide a measure of confidence in the positive effects reported in randomized controlled trials (RCTs). The aim of this study was to calculate the FI of RCTs supporting HCC treatments.

Methods: A methodological systematic review of RCTs in HCC treatments was conducted. Two-arm studies with randomized and positive results for a time-to-event outcome were eligible for the FI calculation.

Results: A total of 6 trails were included in this analysis. The median FI was 0.5 (IQR $0-10)$. FI was $\leq 7$ in 4 (66.7\%) of 6 trials; in those trials the fragility quotient was $\leq 1 \%$.

Conclusion: Many phase 3 RCTs supporting HCC treatments have a low Fl, which challenges the confidence in concluding the superiority of these drugs over control treatments.
\end{abstract}

Keywords: Fragility index, Randomized controlled trials, Endpoint

\section{Background}

Modern medicine is built on evidence-based clinical practice, with randomized controlled trials (RCTs) forming the foundation of such evidence. Because RCTs play important roles in governing clinical practice, the robustness of their results is critical. The results of clinical trials must be valid, reproducible, and repeatable; however, in the context of clinical research, reproducibility and replicability are generally under-researched topics. Historically, $P$ values have been used to indicate statistical the significance of results in clinical trials [1]. Nevertheless, this approach has some significant limitations and has been heavily criticized for being simplistic, with frequent misapplication and misinterpretation [2].

\footnotetext{
*Correspondence: lijingtao555@163.com; 13609645855@163.com ${ }^{2}$ Department of liver diseases (I), The Hospital Affiliated to Shaanxi University of Chinese Medicine, Xianyang 712000, Shaanxi Province, China 'Department of Infectious Diseases, The Key Discipline of Gguangdong Province, The First Affiliated Hospital of Guangzhou Medical University, Guangzhou Medical University, \#151 Yanjiang Road, Guangzhou 510120, Guangdong Province, China
}

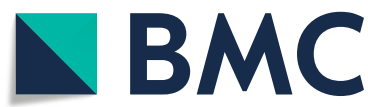

(c) The Author(s). 2021 Open Access This article is licensed under a Creative Commons Attribution 4.0 International License, which permits use, sharing, adaptation, distribution and reproduction in any medium or format, as long as you give appropriate credit to the original author(s) and the source, provide a link to the Creative Commons licence, and indicate if changes were made. The images or other third party material in this article are included in the article's Creative Commons licence, unless indicated otherwise in a credit line to the material. If material is not included in the article's Creative Commons licence and your intended use is not permitted by statutory regulation or exceeds the permitted use, you will need to obtain permission directly from the copyright holder. To view a copy of this licence, visit http://creativecommons.org/licenses/by/4.0/. The Creative Commons Public Domain Dedication waiver (http://creativecommons.org/publicdomain/zero/1.0/) applies to the data made available in this article, unless otherwise stated in a credit line to the data.
The fragility index (FI) is a novel tool, which was developed to assess the robustness of statistically significant dichotomous outcomes from RCTs [3]. It is defined as the minimum number of patients receiving experimental treatment whose status would have to change from a non-event to an event to nullify a meaningful result. A higher FI represents a relativiely robust outcome and indicates that the statistical significance of a given outcome hinges on a greater number of events, whereas a lower FI indicates that the statistical significance of a given outcome depends on only a few events, which suggests a more fragile outcome.

The recommendation of new drugs or treatments for use in clinical practice, mainly depends on the results of phase 3 clinical trials. Thus, this study was performedto analysis to assess the wider implications of the FI in the findings of $\mathrm{HCC}$ treatments in phase 3 clinical trials.

\section{Methods}

This study conducted a methodological systematic review of phase 3 RCTs for HCC treatment. The search terms used were (hepatocellular carcinoma OR 


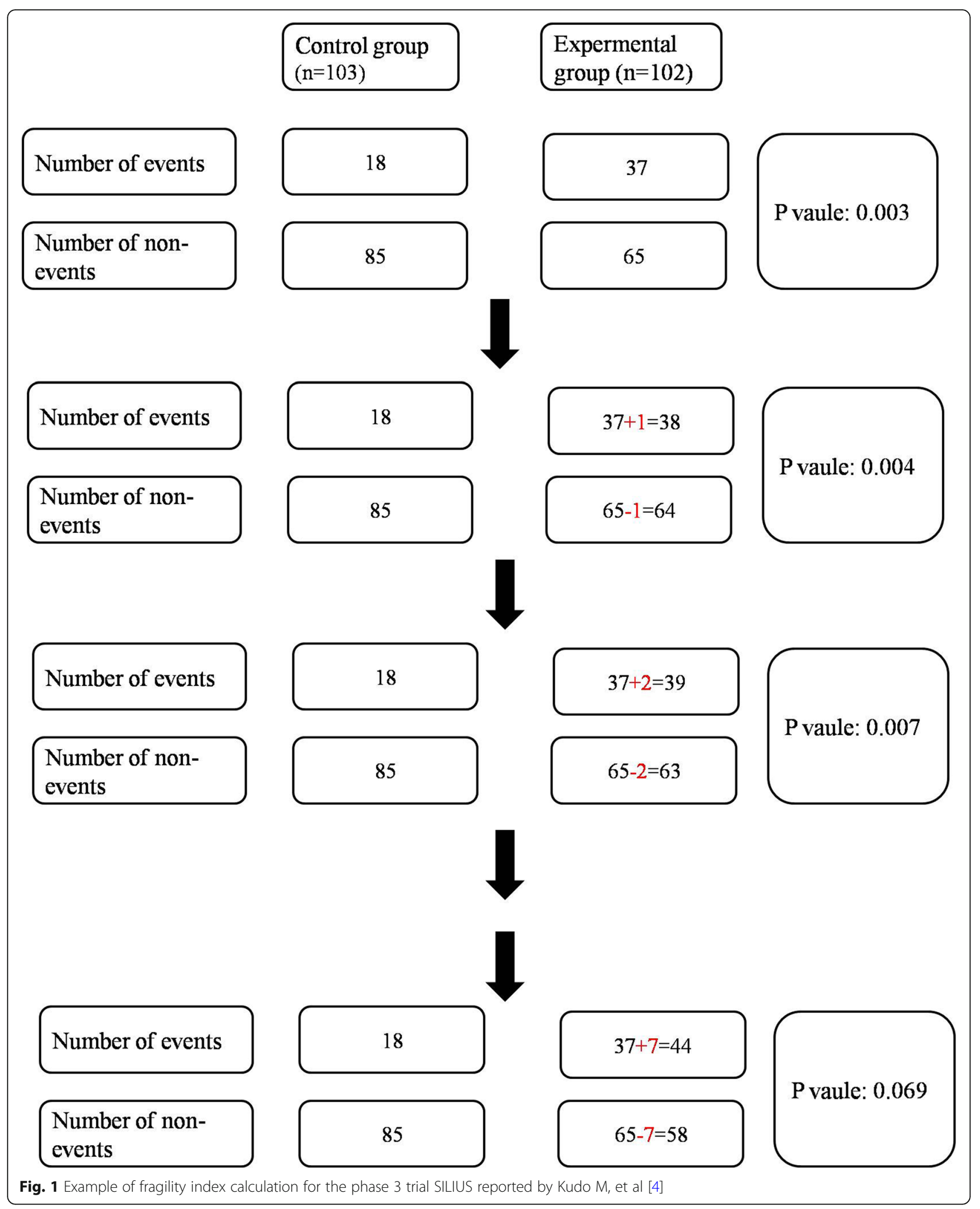




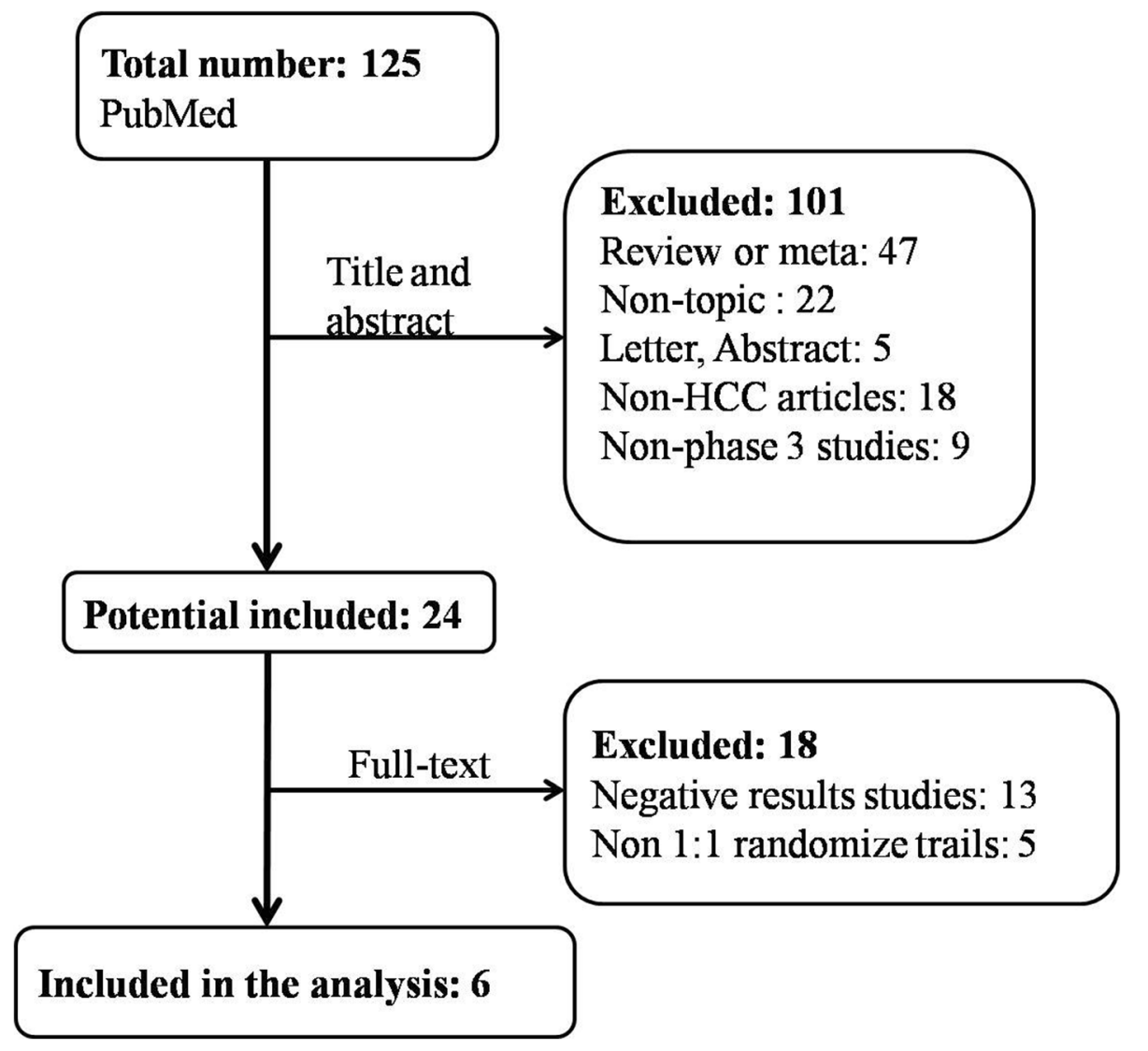

Fig. 2 Flow chart for included studies

hepatocarcinoma OR "liver cancer" OR HCC) AND ("phase 3" OR "phase III"). Only articles published in English were searched for using PubMed search engine and Medline database until August 1, 2019.

For the FI analysis, only two-arm studies with randomization that reported significant positive results with primary or secondary outcomes were included. Data was obtained on trial design, trial number, and the observed numbers of events for the control and experimental groups in primary or secondary time-to-event outcomes. The FI was calculated from a two-by-two contingency table by the iterative addition of an event to the experimental group, which was determined using a web-based fragility calculator (available at http://www.clincalc.com/ Stats/FragilityIndex.aspx). $P$ values were calculated using Fisher's Exact Test. A sample of FI is presented in Fig. 1.

The fragility quotient (FQ) is a metric, that accounts for the FI in the context of sample size [5]. It is described as the FI divided by the total sample size. The usefulness of the FQ lies in its ability to allocate an objective value to the results of subjective importance, and it may be assigned to an outcome with a given FI in a certain sample size [5]. In other words, the FQ assesses the robustness of the FI.

\section{Results}

This study identified 125 records through a series of PubMed searches (Fig. 2). After an initial screening of abstracts and a full-text review of the studies, 6 articles were included in the fragility analysis (Table 1, Fig. 3) [4, 6-10]. The other five RCTs were excluded, as FI can only be calculated in RCTs that allocate 1:1 randomization (Supplementary Table 1). The median sample size for the 6 eligible RCTs was 257 (IQR 220.75-539), and the median FI for the 6 studies was 0.5 (IQR $0-10)$. The $\mathrm{FI} \leq$ was 7 in $4(72.73 \%)$ of 6 trials [7$10]$, and those trials had $\mathrm{FQ}<1 \%$.

Five studies in the fragility analysis were for primary outcome results. Three $(60 \%)$ had primary outcome trials with a FI of 0 (Fisher's exact test $p>0.05$ ), for which a stratified log-rank test was used to calculate the reported significant $P$ value [7-9], and these three (60\%) trials had an FQ $<1 \%$ [7-9]. The article with the highest FI fragility index of 19 was published in the Clinical Cancer Research [6]. However, this study was not a multiple center trial. The remaining 1 study was evaluated with inferior outcome results, whereas non significant differences were found in the primary outcome results. The study of the FI was 1 , and the FQ was less than 1\% [10]. 


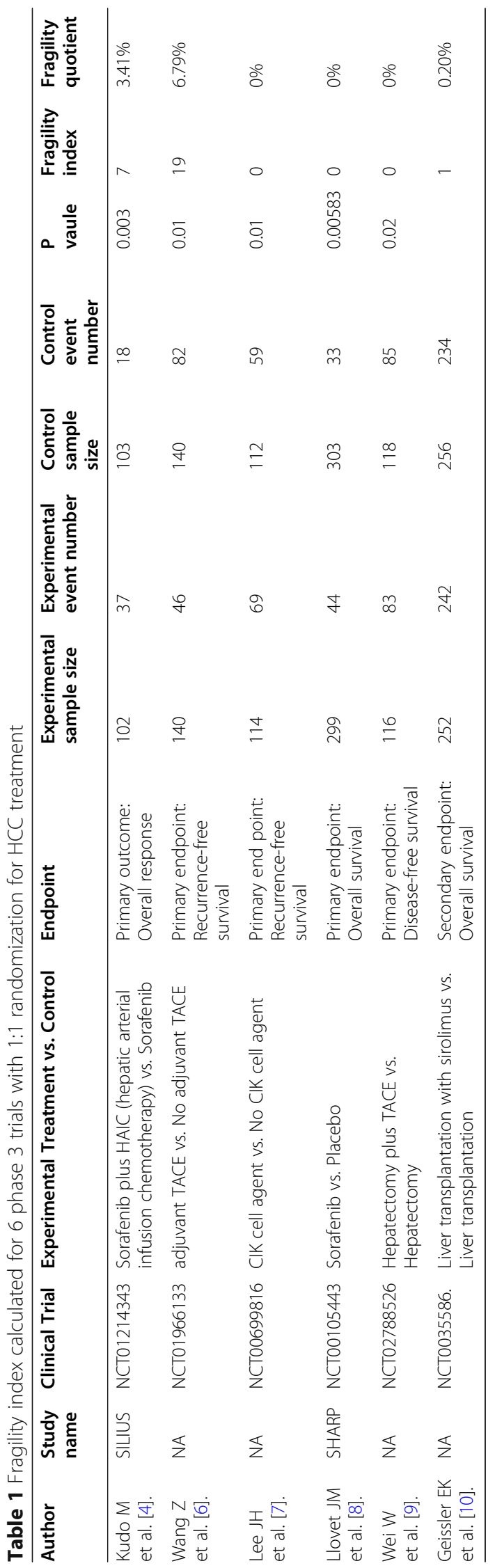




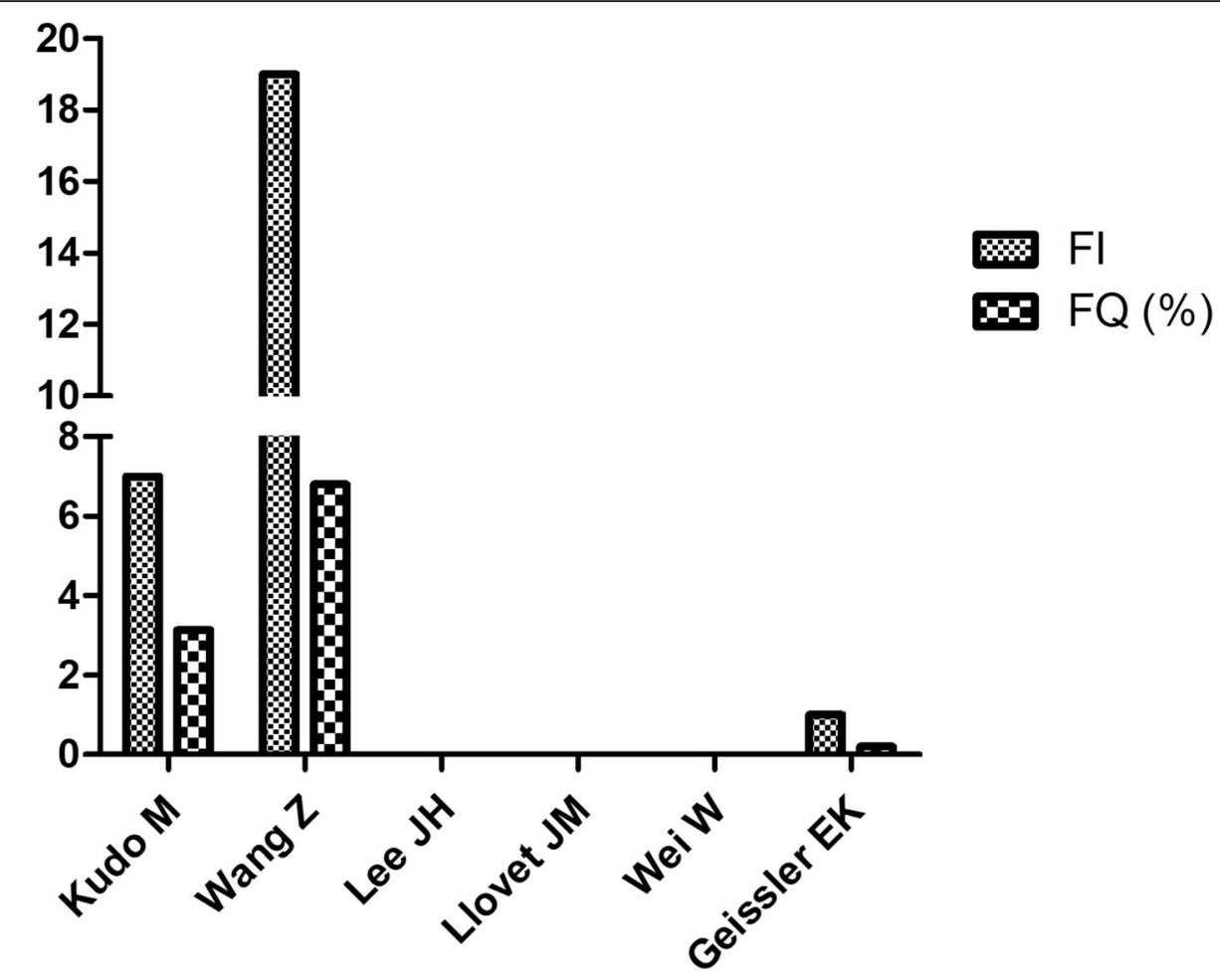

Fig. $3 \mathrm{FI}$ and $\mathrm{FQ}$ in the included studies

\section{Discussion}

To the best of our knowledge, FI investigation for HCC trials has not been performed. The FI has been evaluated in other RCTs, such as emergency medicine [11], giant cell arteritis, Clinical Practice Guidelines [12], and cardiac surgery field [13]. These studies consistently show that many RCTs are fragile, and several researchers have recommended that FI should be adopted in reporting clinical trial outcomes $[12,14]$, our study showed that most results from the randomized trials were far more fragile.

This analysis demonstrated that over $60 \%$ of the phase 3 trials supporting HCC treatments had a low FI; however, they are vulnerable to losing their significance with just a small change in the designation of a small number of events, often equating to $<1 \%$ of the sample size in an experimental group. As clinical practices or the use of drugs approved by Food and Drug Administration are developed on the results of phase 3 clinical trials, the change in the number of events required for fragility raises concerns about a statistical change in the results.

RCTs, particularly phase 3 clinical trials, are likely to remain an important evidence base for clinicians' practice. Despite this, the statistical methodology used to establish significance in such clinical trials has barely evolved. In principle, the $P$ value is an indication of the compatibility among data from a trial; a smaller $\mathrm{P}$ value implies a greater statistical incompatibility of the result with the null hypothesis (an estimation of no difference between the experimental and control group [15]). However, this approach has been greatly criticized for being simplistic, and has frequently been misinterpreted [16]. The log-rank test used in survival data analysis has advantage in that it accounts for events, but it relies on the assumption that the hazard ratio of two treatments remains constant over time. Fisher's exact test, which is used to calculate the FI, has the disadvantage of not accounting for the time-toevent [17]. Thus, the FI is simplistic in its application and resolves some of these shortcomings.

Although the FI and FQ do provide a relative wealth of information when consider alongside other metrics, this study again emphasizes the limitations of the FI itself. First, clinical trials must obtain significant in effects in the treatment group, which means that treatment group got better results compared with control group. These trails could be included to be analyzed by the FI. Many non-inferiority studies cannot be included in this analysis, such as the E7080 trials of lenvatinib for HCC, which produced the same treatment results as sorafenib ${ }^{22}$. Second, because the FI relies on $P$ value, it is essentially an extension of the most frequent approach to data analysis. Thus, it cannot be applied to an outcome of a continuous variable. Third, although many time-to-event outcomes are usually dichotomous, such as mortality, and survival, etc., the FI does not account for the difference in outcomes over time. Particularly in longer studies with variable follow-up time periods, analyses that account for time (such as a Kaplan-Meier curve, or a Cox proportional 
hazards model) are more appropriate than a simple binary outcome analysis. Fourth, our study shows a tendency of the inverse correlation between the FI and $p$-value, which is similar with previous FI studies $[18,19]$. This might be the RCT studies included small number patients. Also, The FI was much higher as the samples increasing [20,21]. Finally, there is no specific cut-off value or lower limit of the FI to classify a study as "either fragile" or "robust".

\section{Conclusion}

The outcomes of many phase 3, RCTs supporting HCC treatments with a low FI challenges the confidence in concluding the superiority of these drugs over control treatments.

\section{Abbreviations}

HCC: Hepatocarcinoma; RCTs: Randomized controlled trials; Fl: Fragility index; FQ: Fragility quotient

\section{Supplementary Information}

The online version contains supplementary material available at https://doi. org/10.1186/s12885-021-08133-8.

Additional file 1: Table S1. The exclusion cause and names of the excluded RCTs as FI can only be calculated in RCTs that allocate 1:1 randomization. Supplementary References.

\section{Acknowledgements}

Not applicable.

\section{Authors' contributions}

All authors were involved in the study design, including setting up the keywords search and project protocol. ZH and LJT collected the data information. ZH draft manuscript. ZWT and LJT were responsible for the supervision of the project and revise of the manuscript. All authors were finally approval of the manuscript.

\section{Funding}

This study was partly supported by the grant from the National Natural Science Foundation of China (No. 81603612); the Science and Technology Department of Shaanxi Province (NO.2018KJXX-093), and Innovation Team of Shaanxi University of Traditional Chinese Medicine (NO.2019-YL05). The funding agencies had no role in study design, data collection and analysis, decision to publish, or preparation of the manuscript.

\section{Availability of data and materials}

Data sharing is not applicable to this article as no datasets were generated or analysed during the current study.

\section{Declarations}

Ethics approval and consent to participate

Not applicable.

\section{Consent for publication}

Not applicable.

\section{Competing interests}

The authors declare that they have no competing interests
Received: 30 December 2019 Accepted: 16 December 2020

Published online: 09 April 2021

\section{References}

1. Amrhein V, Greenland S, McShane B. Scientists rise up against statistical significance. NATURE. 2019;567(7748):305-7. https://doi.org/10.1038/d41586019-00857-9.

2. Ioannidis J. The Proposal to Lower P Value Thresholds to .005. JAMA. 2018; 319(14):1429-30. https://doi.org/10.1001/jama.2018.1536.

3. Walsh M, Srinathan SK, McAuley DF, Mrkobrada M, Levine O, Ribic C, et al. The statistical significance of randomized controlled trial results is frequently fragile: a case for a fragility index. J Clin Epidemiol. 2014;67(6):622-8. https:// doi.org/10.1016/j.jclinepi.2013.10.019.

4. Kudo M, Ueshima K, Yokosuka O, Ogasawara S, Obi S, Izumi N, et al. Sorafenib plus low-dose cisplatin and fluorouracil hepatic arterial infusion chemotherapy versus sorafenib alone in patients with advanced hepatocellular carcinoma (SILIUS): a randomised, open label, phase 3 trial. Lancet Gastroenterol Hepatol. 2018;3(6):424-32. https://doi.org/10.1016/\$24 68-1253(18)30078-5.

5. Ahmed W, Fowler RA, McCredie VA. Does sample size matter when interpreting the fragility index? Crit Care Med. 2016;44(11):e1142-3. https:// doi.org/10.1097/CCM.0000000000001976.

6. Wang Z, Ren Z, Chen Y, Hu J, Yang G, Yu L, et al. Adjuvant Transarterial chemoembolization for HBV-related hepatocellular carcinoma after resection: a randomized controlled study. Clin Cancer Res. 2018;24(9):207481. https://doi.org/10.1158/1078-0432.CCR-17-2899.

7. Lee JH, Lee JH, Lim YS, Yeon JE, Song TJ, Yu SJ, et al. Adjuvant immunotherapy with autologous cytokine-induced killer cells for hepatocellular carcinoma. Gastroenterology. 2015;148(7):1383-91. https:// doi.org/10.1053/j.gastro.2015.02.055.

8. Llovet JM, Ricci S, Mazzaferro V, Hilgard P, Gane E, Blanc JF, et al. Sorafenib in advanced hepatocellular carcinoma. N Engl J Med. 2008;359(4):378-90. https://doi.org/10.1056/NEJMoa0708857.

9. Wei W, Jian PE, Li SH, Guo ZX, Zhang YF, Ling YH, et al. Adjuvant transcatheter arterial chemoembolization after curative resection for hepatocellular carcinoma patients with solitary tumor and microvascular invasion: a randomized clinical trial of efficacy and safety. Cancer Commun (Lond). 2018;38(1):61. https://doi.org/10.1186/s40880-018-0331-y.

10. Geissler EK, Schnitzbauer AA, Zulke C, Lamby PE, Proneth A, Duvoux C, et al. Sirolimus use in liver transplant recipients with hepatocellular carcinoma: a randomized, multicenter, open-label phase 3 trial. Transplantation. 2016: 100(1):116-25. https://doi.org/10.1097/TP.0000000000000965.

11. Brown J, Lane A, Cooper C, Vassar M. The results of randomized controlled trials in emergency medicine are frequently fragile. Ann Emerg Med. 2019; 73(6):565-76. https://doi.org/10.1016/j.annemergmed.2018.10.037.

12. Edwards E, Wayant C, Besas J, Chronister J, Vassar M. How fragile are clinical trial outcomes that support the CHEST clinical practice guidelines for VTE? CHEST. 2018;154(3):512-20. https://doi.org/10.1016/j.chest.2018.01.031.

13. Gaudino M, Hameed I, Biondi-Zoccai G, Tam DY, Gerry S, Rahouma M, et al. Systematic evaluation of the robustness of the evidence supporting current guidelines on myocardial revascularization using the fragility index. Circ Cardiovasc Qual Outcomes. 2019;12(12):e6017.

14. Berti A, Cornec D, Medina IJ, Matteson EL, Murad MH. Treatments for giant cell arteritis: meta-analysis and assessment of estimates reliability using the fragility index. Semin Arthritis Rheum. 2018;48(1):77-82. https://doi.org/10.1 016/j.semarthrit.2017.12.009.

15. Demidenko E. The p-value you Can't buy. Am Stat. 2016;70(1):33-8. https:// doi.org/10.1080/00031305.2015.1069760.

16. Sterne JA, Davey SG. Sifting the evidence-what's wrong with significance tests? BMJ. 2001;322(7280):226-31. https://doi.org/10.1136/bmj.322.7280.226.

17. Bewick V, Cheek L, Ball J. Statistics review 12: survival analysis. Crit Care. 2004;8(5):389-94. https://doi.org/10.1186/cc2955.

18. Wayant C, Meyer C, Gupton R, Som M, Baker D, Vassar M. The fragility index in a cohort of HIV/AIDS randomized controlled trials. J Gen Intern Med. 2019;34(7):1236-43. https://doi.org/10.1007/s1 1606-019-04928-5.

19. Pedziwiatr M, Mizera M, Wysocki M, Malczak P, Stefura T, Gajewska N, et al. The fragility of statistically significant results from clinical nutrition randomized controlled trials. Clin Nutr. 2020;39(4):1284-91. https://doi.org/1 0.1016/j.clnu.2019.05.024 
20. Carter RE, McKie PM, Storlie CB. The fragility index: a P-value in sheep's clothing? Eur Heart J. 2017;38(5):346-8. https://doi.org/10.1093/eurheartj/ ehw495.

21. Majeed M, Agrawal R, Attar BM, Kamal S, Patel P, Omar YA, et al. Fragility index: how fragile is the data that support the American College of Gastroenterology guidelines for the management of Crohn's disease? Eur J Gastroenterol Hepatol. 2020;32(2):193-8. https://doi.org/10.1097/MEG. 0000000000001635 .

\section{Publisher's Note}

Springer Nature remains neutral with regard to jurisdictional claims in published maps and institutional affiliations.

- fast, convenient online submission

- thorough peer review by experienced researchers in your field

- rapid publication on acceptance

- support for research data, including large and complex data types

- gold Open Access which fosters wider collaboration and increased citations

- maximum visibility for your research: over $100 \mathrm{M}$ website views per year

At $\mathrm{BMC}$, research is always in progress. 